\title{
ARTICLE OPEN \\ On the dynamic instability of Arctic sea ice
}

\author{
Jean-Paul Chavas ${ }^{1}$ and Corbett Grainger ${ }^{1}$
}

The last few decades have seen a significant decline in Arctic sea ice, generating concerns about both its causes and its longer-term implications. In this paper, we introduce an empirical technique to examine the dynamics of Arctic sea ice extent. Using quantile autoregression, we find that the negative effect of atmospheric $\mathrm{CO}_{2}$ is stronger in the upper tail of the ice distribution. We also document that Arctic sea ice dynamics have become more unstable over the last three decades, especially during the summer. The rising summer instability occurs across quantiles, indicating that it is due to the joint effects of rising atmospheric $\mathrm{CO}_{2}$ and nonlinear feedbacks (and not due to outside shocks). While we do not find evidence of "critical slowing", we see the increasing instability as a cause for concern. We also use the model to predict the evolution of Arctic sea ice extent under alternative $\mathrm{CO}_{2}$ concentration scenarios.

npj Climate and Atmospheric Science (2019)2:23 ; https://doi.org/10.1038/s41612-019-0080-x

\section{INTRODUCTION}

This paper investigates the recent evolution of Arctic sea ice extent and the factors affecting its dynamics using a novel empirical technique. As showed in Fig. 1, Arctic sea ice has declined rapidly over the last four decades, generating questions about its underlying dynamics. The generation and melting of sea ice are affected by energy flux involving seasonal variations in solar radiation and thermodynamic exchange and heat transport in the atmosphere and ocean. ${ }^{1-7}$ Heat exchanges are associated with feedback effects arising in albedo and in atmospheric and ocean circulations that fluctuate over space and time. These feedback effects generate complex nonlinear dynamics that can generate instability in climate. ${ }^{8}$

A concern raised in the literature is that the nonlinear dynamics could generate "tipping points," or thresholds after which a system changes irreversibly. Polar sea ice is an important example, with positive ice-albedo feedback contributing to the recent decline in Arctic ice. ${ }^{9}$ Many previous studies focus on thresholds and bifurcations in Arctic sea ice extent using climate models (e.g., ${ }^{1,3}$ ) but statistically identifying critical thresholds remains a challenge. ${ }^{7,10}$ Moreover, assessing the linkages between climate change and Arctic sea ice loss remains difficult. ${ }^{11,12}$ This is due in large part to the complexity of feedback effects: while ice-albedo is important, ${ }^{13}$ there are also spatial and temporal feedback effects related to atmospheric and ocean circulation. ${ }^{3,7,14,15}$ Incomplete knowledge about these feedback effects makes it difficult to evaluate Arctic sea ice dynamics and its longer-term implications. Such evaluations become even more challenging considering the seasonality of solar radiation and the recent increase in anthropogenic $\mathrm{CO}_{2}$ emissions. ${ }^{14,16,17}$ We argue that changing atmospheric $\mathrm{CO}_{2}$ affects the seasonality and nonlinear dynamics of Arctic sea ice. This is important as it makes covariance analyses (e.g., using autocovaraince or spectral decomposition) unfit to the study of ice dynamics. This paper addresses these challenges by studying how nonlinear dynamics and anthropogenic $\mathrm{CO}_{2}$ emissions affect the instability of Arctic sea ice extent.
Using data on Arctic sea ice extent over the last 40 years, we employ quantile regression to study the evolution of the distribution of Arctic sea ice extent. The paper specifies and estimates a quantile autoregression model that includes interaction effects between seasonality, $\mathrm{CO}_{2}$ concentrations, dynamics and the stochastic distribution of Arctic sea ice extent extent. The analysis provides new and useful information on the dynamic stability of Artic sea ice.

\section{RESULTS}

The dynamics of Arctic sea ice is complex: it involves spatial and temporal effects of solar influx and heat transfers toward the Arctic from the atmosphere and ocean. ${ }^{3,5,7,18,19}$ Dynamic feedbacks include ice albedo $1,2,9,10,13,20,21$ and the effects of greenhouse gases that restrict long-wave radiation to space, contributing to the melting of Arctic sea ice extent. ${ }^{22,23}$ In addition, seasonality along with atmospheric and ocean circulations have large impacts on polar climate..$^{24-26}$ Our analysis relies on a representation of Arctic ice extent given in Eq. (2) below. As discussed in the method section, Eq. (2) is a stochastic nonlinear difference equation corresponding to a "final form" of Arctic ice extent dynamics. ${ }^{27}$ It goes beyond the mean and variance analysis commonly found in previous research relying on autocorrelation or spectral analysis (e.g., ${ }^{28}$ ).

In our empirical analysis, Arctic sea ice extent ice ${ }_{t}$ in (2) was obtained from the National Snow \& Ice Data Center ${ }^{29}$ and atmospheric $\mathrm{CO}_{2}$ was measured at the Mauna Loa Observatory and obtained from NOAA. ${ }^{30}$ Summary statistics of the data are presented in Table 1.

Our investigation proceeds in two steps. First, Eq. (2) is estimated as a standard regression model, providing estimates of the evolution of mean Arctic sea ice. The regression results are reported in Table 2. Second, treating ice as a stochastic variable, we want to explore not just the mean but also the distribution of Arctic sea ice extent as it evolves over time. Below, we explore this issue by estimating Eq. (2) as a quantile regression model, the

${ }^{1}$ Department of Agricultural and Applied Economics, University of Wisconsin, Madison, WI 53706, USA

Correspondence: Jean-Paul Chavas (jchavas@wisc.edu)

Received: 29 May 2018 Accepted: 20 June 2019

Published online: 11 July 2019 


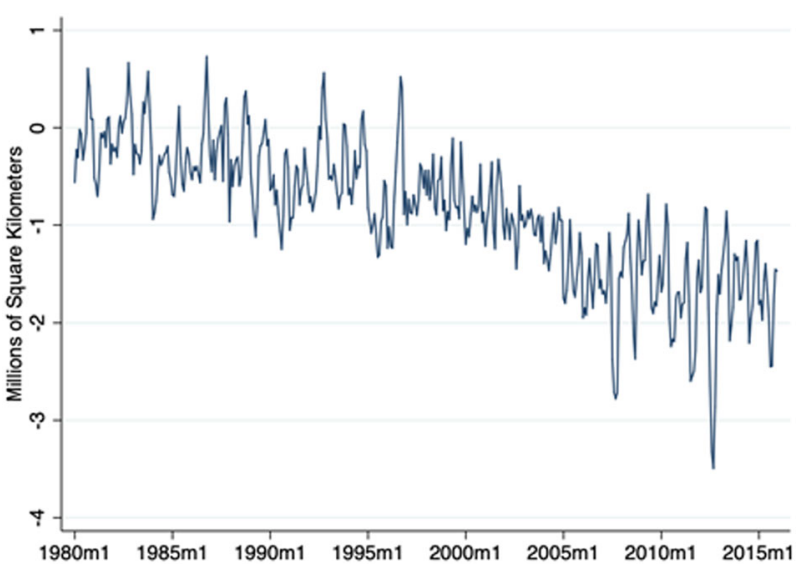

Fig. 1 Historical Arctic Sea Ice Extent (Monthly Anomalies Relative to Pre-1980). Source: Windnagel et al. ${ }^{29}$ Authors' own calculations. Monthly anomalies (measured in millions of $\mathrm{km}^{2}$ ) from pre-1980 averages

\begin{tabular}{|lcccc|}
\hline \multicolumn{4}{l}{ Table 1. } & Summary statistics \\
Variables & Mean & Median & Minimum & Maximum \\
\hline Arctic Sea Ice Extent & 11.49 & 12.15 & 3.56 & 16.34 \\
$\mathrm{CO}_{2}$ (ppmv) & 368.4 & 366.4 & 334.0 & 409.6 \\
\hline
\end{tabular}

Note: The variables are monthly observations over the period 1979-2017. Arctic Sea Ice Extent is measured in millions of square kilometers

\begin{tabular}{|c|c|c|}
\hline \multirow[t]{2}{*}{ Variables } & \multicolumn{2}{|l|}{ Arctic sea ice, ice ${ }_{t}$} \\
\hline & Parameter Estimate & Standard Error \\
\hline Intercept & $7.2319^{a}$ & 1.0705 \\
\hline $\mathrm{CO}_{2}$ & $-0.0077^{\mathrm{a}}$ & 0.0019 \\
\hline ice $_{t-1}$ & $1.4535^{\mathrm{a}}$ & 0.1374 \\
\hline ice $_{t-2}$ & $-1.0643^{a}$ & 0.0801 \\
\hline ice $_{t-12}$ & $0.1883^{b}$ & 0.0744 \\
\hline sine & -0.3811 & 0.5740 \\
\hline cosine & $2.7429^{a}$ & 0.4394 \\
\hline ice $_{t-1} \times$ ice $_{t-2}$ & 0.0077 & 0.0065 \\
\hline ice $_{t-1} \times$ ice $_{t-12}$ & $-0.0842^{a}$ & 0.0083 \\
\hline ice $_{t-2} \times$ ice $_{t-12}$ & $0.0820^{a}$ & 0.0115 \\
\hline $\mathrm{CO}_{2} \times$ sine & 0.0019 & 0.0012 \\
\hline $\mathrm{CO}_{2} \times$ cosine & $-0.0025^{\mathrm{b}}$ & 0.0010 \\
\hline R-squared & 0.992 & \\
\hline Residual standard error & 0.288 & \\
\hline F statistics & $5094^{\mathrm{a}}$ & \\
\hline $\mathrm{BIC}$ & 228.54 & \\
\hline
\end{tabular}

Note: The standard errors were obtained using bootstrapping. Stars indicates the significance level

${ }^{a}$ Means significant at the 1 percent level

${ }^{\mathrm{b}}$ Means significant at the 5 percent level

'Means significant at the 10 percent level
Table 3. Quantile estimation of the distribution of arctic sea ice, Eq. (2), selected quantiles

\begin{tabular}{|c|c|c|c|c|c|}
\hline \multirow[t]{2}{*}{ Variables } & \multicolumn{5}{|l|}{ Quantiles } \\
\hline & $q=0.1$ & $q=0.3$ & $q=0.5$ & $q=0.7$ & $q=0.9$ \\
\hline Intercept & $6.2601^{a}$ & $6.2227^{a}$ & $5.3296^{\mathrm{a}}$ & $5.9242^{a}$ & $10.2199^{a}$ \\
\hline $\mathrm{CO}_{2}$ & $-0.0051^{\mathrm{b}}$ & $-0.0061^{a}$ & $-0.0054^{a}$ & $-0.0061^{a}$ & $-0.0126^{\mathrm{a}}$ \\
\hline ice $_{t-1}$ & $1.2904^{\mathrm{a}}$ & $1.2379^{\mathrm{a}}$ & $1.1392^{\mathrm{a}}$ & $1.2848^{\mathrm{a}}$ & $1.6575^{\mathrm{a}}$ \\
\hline ice $_{t-2}$ & $-1.0111^{a}$ & $-0.9793^{a}$ & $-0.8698^{a}$ & $-0.9161^{a}$ & $-1.1086^{\mathrm{a}}$ \\
\hline ice $_{t-12}$ & 0.1130 & $0.2686^{a}$ & $0.3534^{\mathrm{a}}$ & $0.2986^{\mathrm{b}}$ & 0.0508 \\
\hline sine & $-2.0456^{a}$ & $-1.4615^{\mathrm{a}}$ & -0.8620 & -0.0522 & -0.3904 \\
\hline cosine & $1.7828^{\mathrm{a}}$ & $2.4583^{b}$ & $2.0940^{\mathrm{a}}$ & $2.9693^{a}$ & $2.3330^{\mathrm{a}}$ \\
\hline ice $_{t-1} \times$ ice $_{t-2}$ & 0.0088 & $0.0179^{a}$ & $0.0186^{b}$ & 0.0085 & -0.0099 \\
\hline ice $_{t-1} \times$ ice $_{t-12}$ & $-0.0510^{a}$ & $-0.0678^{a}$ & $-0.0635^{\mathrm{a}}$ & $-0.0754^{a}$ & $-0.0914^{a}$ \\
\hline ice $_{t-2} \times$ ice $_{t-12}$ & $0.0599^{a}$ & $0.0608^{a}$ & $0.0533^{a}$ & $0.0707^{a}$ & $0.0994^{\mathrm{a}}$ \\
\hline $\mathrm{CO}_{2} \times$ sine & $0.0058^{a}$ & $0.0043^{c}$ & 0.0023 & 0.0006 & 0.0032 \\
\hline $\mathrm{CO}_{2} \times$ cosine & -0.0012 & -0.0021 & $-2.654^{\mathrm{a}}$ & -0.0036 & -0.0017 \\
\hline
\end{tabular}

Note: The standard errors were obtained using bootstrapping. Stars indicates the significance level

${ }^{a}$ Means significant at the 1 percent level

${ }^{\mathrm{b}}$ Means significant at the 5 percent level

${ }^{c}$ Means significant at the 10 percent level

quantile function being the inverse of the associated distribution function. ${ }^{31}$ Quantile regression consists in estimating the quantile function conditional on a set of explanatory variables. It provides a flexible representation of the quantile/distribution function in the sense that it allows the parameters to vary across quantiles. ${ }^{31}$ For the 0.5 quantile, this corresponds to estimating the conditional median (also known as least absolute deviations). More generally, as the quantile varies between 0 and 1 , quantile regression generates estimates of the whole quantile function (with the distribution function as its inverse). Applied to Eq. (2), quantile regression provides estimates of the conditional quantile functions for Arctic sea ice extent. In turn, this gives us a basis to investigate the distribution of Arctic sea ice extent and the factors affecting its evolution over time. ${ }^{31,32}$ The quantile regression estimates are presented in Table 3 for selected quantiles $q, q=0.1$, $0.3,0.5,0.7$ and 0.9 .

The estimates reported in Tables 2 and 3 show the importance of dynamics. Most of the lagged ice variables are statistically significant. They include short term effects associated with (ice ${ }_{t-1}$, ice $\left._{t-2}\right)$ and longer-term effects associated with ice ${ }_{t-12}$. They also include nonlinear dynamics as most of the interaction effects among lagged variables are statistically significant at the $5 \%$ level. As discussed below, the coefficients of the interaction variables can strengthen lagged effects and contribute to rising dynamic instability. Tables 2 and 3 also document the importance of seasonality as reflected by the significance of the sine and cosine terms. The effects of $\mathrm{CO}_{2}$ on Arctic sea ice are found to be negative and statistically significant. This is consistent with the evidence that rising $\mathrm{CO}_{2}$ is a contributing factor to the decline in Arctic sea ice extent. Finally, the estimates reported in Tables 2 and 3 show that $\mathrm{CO}_{2}$ interacts with the sine and cosine terms, indicating greenhouse gases are contributing to reducing the seasonality of Arctic sea ice extent. The estimates reported in Table 2 imply that the amplitude of seasonal variations has declined by $11 \%$ between 1981 and 2017. This adds to the evidence that increases in atmospheric $\mathrm{CO}_{2}$ have been associated with a decline in Arctic sea ice seasonality. ${ }^{16}$ This suggests that it is critical to model dynamics flexibly, allowing seasonality to vary with $\mathrm{CO}_{2}$ concentrations. 
The quantile estimates of Eq. (2) provide insights into the nonlinear dynamics of Arctic sea ice extent. First, the quantile estimates reported in Table 3 show that the factors affecting Arctic sea ice extent can have different impacts across quantiles. We tested the null hypothesis that the non-intercept parameters in (2) are the same across quantiles, which we strongly reject at the 1 percent significance level. For example, Table 3 shows that the negative effect of $\mathrm{CO}_{2}$ is stronger in the upper tail of the distribution $(q=0.9)$, indicating that $\mathrm{CO}_{2}$ interacts with other shocks affecting Arctic sea ice. Table 3 also shows that the coefficient of ice $_{t-1}$ is much larger in the upper tail of the distribution $(q=0.9)$, reflecting that positive feedbacks are stronger when other shocks contribute to build Arctic sea ice. Finally, Table 3 shows that interaction effects among lagged ice (ice $_{t-i} \times$ ice $_{t-j}$ ) vary across quantiles, reflecting that feedback effects depend on both past values and current shocks. Capturing such effects is a novel and important feature of our approach.

Second, the quantile estimates of Eq. (2) can be used to evaluate the path of the distribution of Arctic sea ice over the sample period 1980-2017. Conditional on the observed values of the explanatory variables in (2), Fig. 2 reports this path expressed in terms of mean, standard deviation and skewness of Arctic sea ice extent. Figure 2 shows the dominant role of seasonality. The low standard deviation reflects that the specification (2) provides a very good fit to the data. Figure 2 also indicates that the probability distribution of Arctic is not symmetric: it is positively skewed, reflecting that the probability of being in the upper tail of the distribution ("more ice") is higher than the probability of being in the lower tail ("less ice"). We tested the null hypothesis that the distribution is symmetric (i.e., with zero skewness) and rejected this hypothesis at the 10 percent significance level. Finding that the conditional distribution of Arctic sea ice extent is skewed stresses the need to go beyond mean and variance in the analysis of ice dynamics. Finally, Fig. 2 shows that skewness varies with the season, another indication of interactions between seasonality and dynamics.

The estimates reported in Table 3 provide useful information on the factors affecting Arctic sea ice dynamics. Our analysis focuses on three issues: $1 /$ what are the implications of our analysis for dynamic instability of Arctic sea ice? 2/ what are the longer-term effects of $\mathrm{CO}_{2}$ ? And 3/ what do they imply for the evolution and potential disappearance of Arctic sea ice over the next few decades?

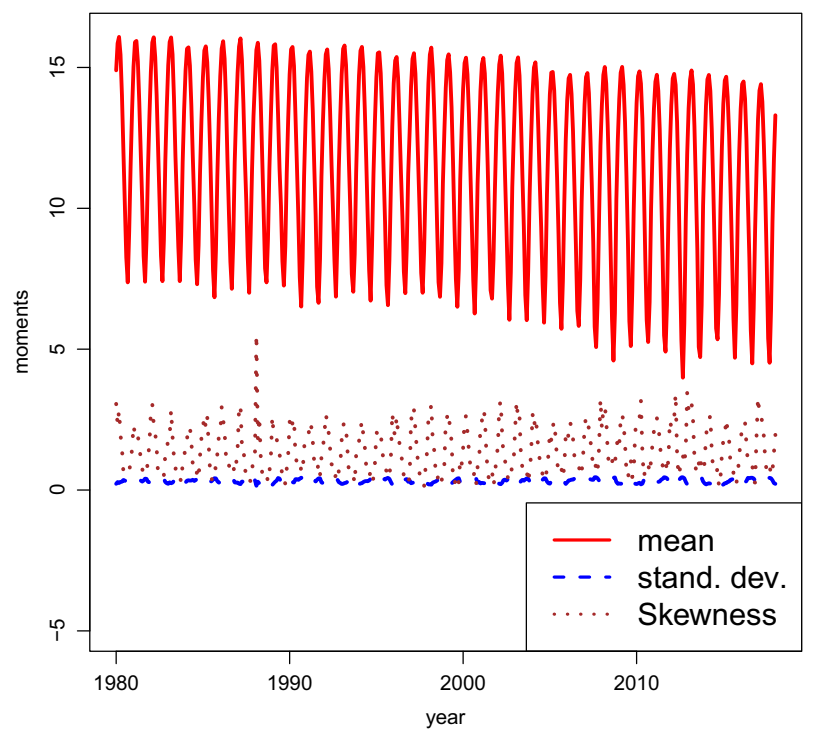

Fig. 2 Estimated Moments for Arctic Sea Ice, 1979-2017
Equation (2) gives a parametric representation of the nonlinear dynamics in Arctic sea ice. As discussed in the online supplemental material to this article, the quantile estimates of Eq. (2) provide the information to evaluate the dynamic stability of Arctic sea ice. This can be done by obtaining the characteristic roots associated with the dynamic system (see the online supplemental material to this article). Letting $\lambda_{1}$ be the dominant root evaluated in a given neighborhood, $\log \left(\left|\lambda_{1}\right|\right)$ measures the rate of divergence

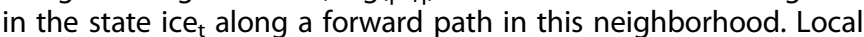
dynamic stability is associated with $\left|\lambda_{1}\right|<1$, while $\left|\lambda_{1}\right|>1$ implies local instability.

\section{DISCUSSION}

On the basis of the quantile estimates of Eq. (2), we evaluated the dominant root evaluated under alternative scenarios. The estimated roots are presented in Figs. 3 and 4 for different quantiles and at different times. Figure 3 shows the dominant root for February 1985 and 2015 while Fig. 4 shows it for August 1985 and 2015. In February, the root is below 1 for all quantiles and all years. But in August, the root is around 1 or slightly greater than 1, indicating that dynamic instability is more prevalent in the summer. In addition, comparing 1985 and 2015, Fig. 4 indicates that, in August, the dominant root is increasing over time and getting to the instability zone (where $\lambda_{1}>1$ ). This is a critical result: we find evidence that that Arctic sea ice has become more unstable over the last four decades. The changing instability is due to the nonlinear dynamics: strong dynamic nonlinear feedbacks contribute to the increased dynamic instability in Arctic sea ice extent.

Figure 5 provides additional information on the seasonality of instability. It reports the dominant root for different months in 2015. It shows that the dominant root tends to be lowest in December and highest in August; further, it is rising in the Spring and declining in in the Fall. This documents much seasonality in Arctic sea ice dynamics and the presence of instability (when the dominant root is greater than 1) only in the summer. Interestingly, the instability (as measured by the dominant root) is found to be highest in August: it occurs earlier than the period of minimal ice extent (which is typically in September). Finding that the instability is seasonal is important: we think that it is why previous

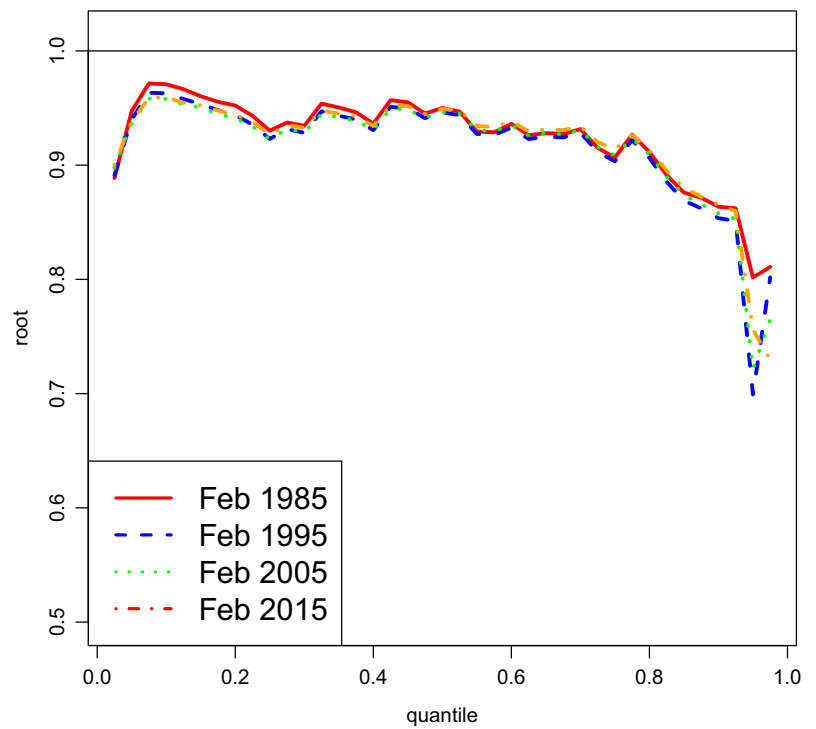

Fig. 3 Dynamics of Arctic sea ice: the dominant root in February for selected years. Note: the dominant roots are plotted across quantiles for selected months and years. A dominant root at or above 1 indicates instability 


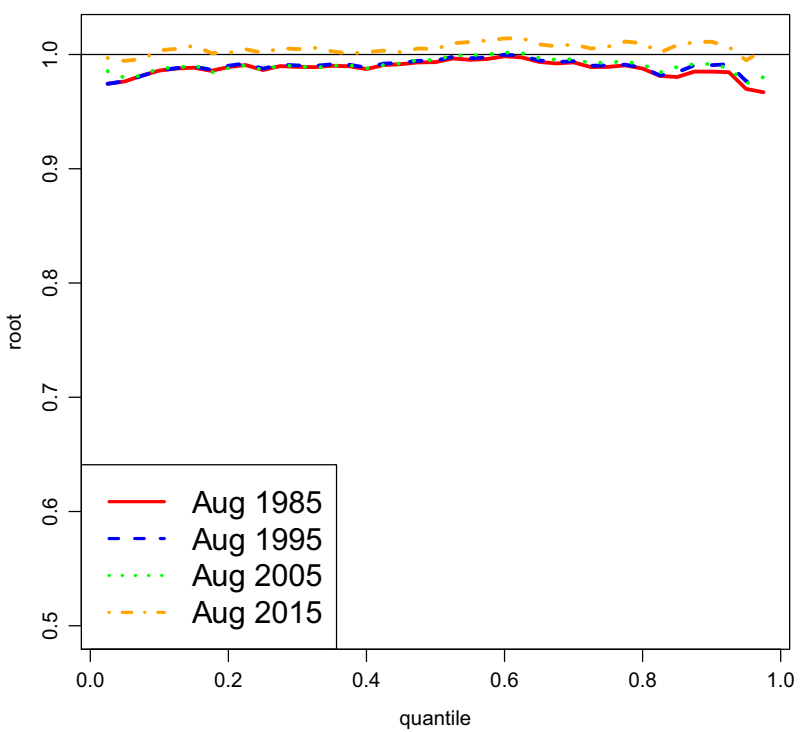

Fig. 4 Dynamics of Arctic Sea Ice: The dominant root in August for selected years. Note: the dominant roots are plotted across quantiles for selected months and years. A dominant root at or above 1 indicates instability. Figure 4 shows increasing instability over time in August

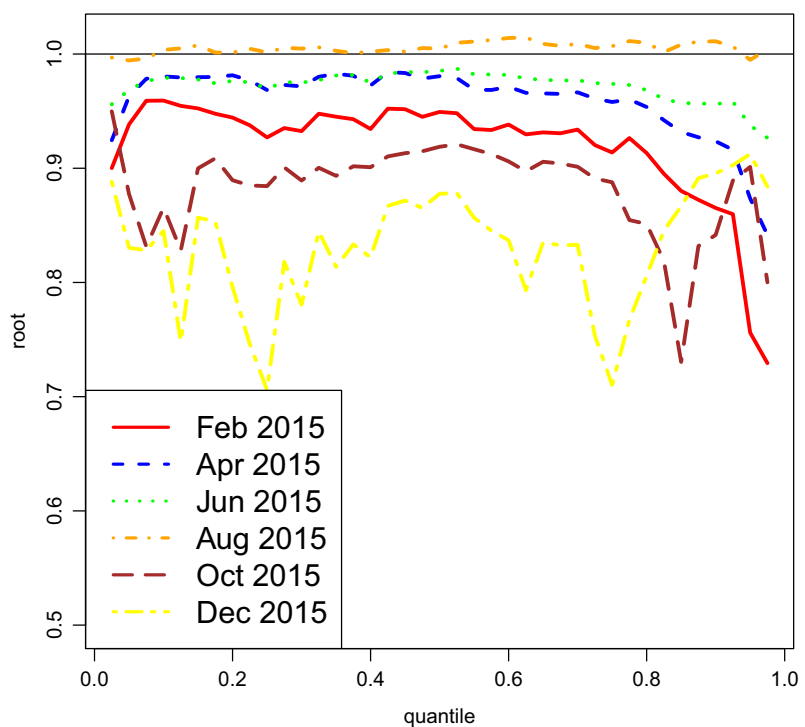

Fig. 5 Instability and Seasonality: dominant root for selected months, 2015. Note the dominant roots for selected months in 2015 are plotted across quantiles. A dominant root at or above 1 indicates instability. Figure 5 shows that instability is highest in August and lowest in December

research has had difficulties documenting dynamic instability in Arctic sea ice (e.g., ${ }^{21}$ )

Figure 5 indicates that Arctic sea ice is becoming more unstable. How strong is this evidence? To answer this question, note that the dominant roots in Figs 3 and 4 are function of the quantile parameter estimates (as reported in Table 3). Treating these estimates as random variables, it follows that the roots are also random variables. As noted above, local instability corresponds to $\lambda_{1}>1$. We use bootstrapping to evaluate the distribution of the estimated roots under alternative scenarios. In this context, we can evaluate the probability $\operatorname{Prob}\left(\lambda_{1}>1\right)$, i.e., that the probability that Arctic sea ice is dynamically unstable. The results are presented in Fig. 6.

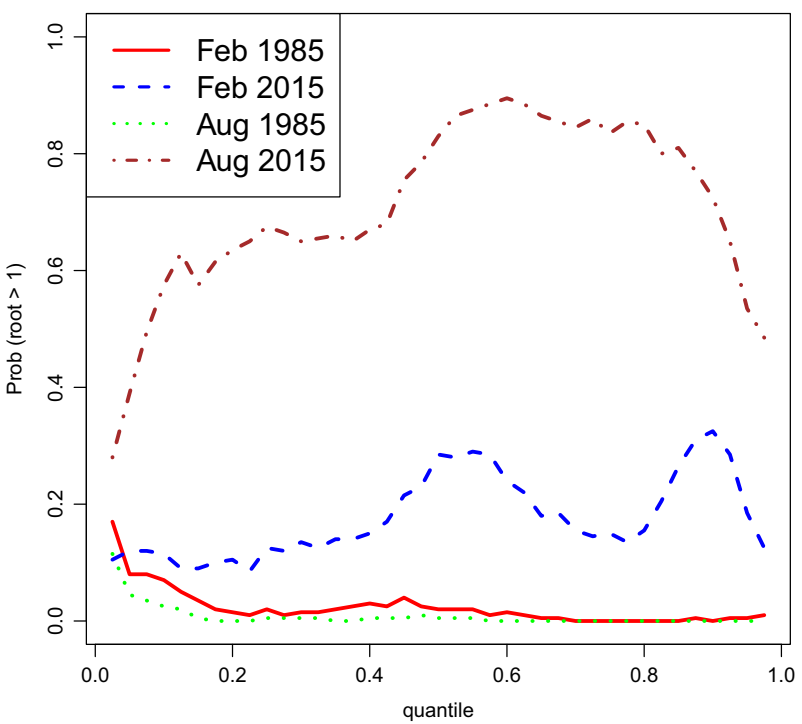

Fig. 6 Rising dynamic instability: prob(root $>1$ ) across quantiles. Note: the probabilities of unstable dynamics (Prob(root $>1)$ ) are plotted across quantiles. In a way consistent with Fig. 3-6 shows that dynamic instability in Arctic sea ice is higher in August and that it increases over time

Figure 6 shows the probability $\operatorname{Prob}\left(\lambda_{1} \geq 1\right)$ at different time periods. Again, Fig. 6 documents that the instability of Arctic sea ice has a strong seasonal component. The probability of dynamic instability is basically non-existent in February, but it is much higher in August. In other words, Arctic sea ice instability arises but only during the summer period. Figure 6 also documents how the dynamic instability in August has been increasing over time. Between 1985 and 2015, the probability of dynamic instability has more than doubled across almost quantiles. This has three important implications. First, finding that this result applies across quantiles indicates the rising summer instability is not due to outside shocks. Rather it is due to the joint effects of rising $\mathrm{CO}_{2}$ and nonlinear feedback (as captured in model (2)). Second, $\mathrm{CO}_{2}$ is the key variable that is changing over time in model (2). It means that we can associate the increased summer instability to the effects of rising atmospheric $\mathrm{CO}_{2}$. Third, as noted above, finding rising instability only in the summer indicates the empirical difficulty of uncovering evidence of ice instability in the presence of strong seasonality. Finally, our analysis finds that the increasing instability is happening "slowly". In that sense, our analysis does not find evidence of a "tipping point" (as tipping points would suggest a rapid rise in instability when the tipping point is crossed).

Figures 7 and 8 presents the simulated evolution of Arctic sea ice over the next few decades. This is done by conducting forward stochastic simulations of our estimated quantile model under alternative $\mathrm{CO}_{2}$ scenarios. Five scenarios are presented, each scenario starting in 2017 and corresponding to a different annual growth in atmospheric $\mathrm{CO}_{2}:+0 \%,+0.5 \%,+1 \%,+1.5 \%$ and $+2 \%$. The $0 \%$ scenario assumes (somewhat unrealistically) that $\mathrm{CO}_{2}$ emission policy would be put in place to keep future atmospheric $\mathrm{CO}_{2}$ at 2017 levels. The $+0.5 \%$ scenario is close to what has been observed over the last 40 years. ${ }^{30}$ The other scenarios $(+1 \%$, $+1.5 \%$ and $+2 \%$ ) represent more pessimistic situations about the growth in greenhouse gases over the next few decades.

Figure 7 reports the simulated results for February while Fig. 8 reports them for August. First, over the next decade, Figs 7 and 8 show that the impacts of rising atmospheric $\mathrm{CO}_{2}$ on Arctic sea ice are relatively small. But the longer-term impact could be substantial. This stresses the importance of understanding the underlying dynamics. Second, as expected, Arctic sea ice extent 


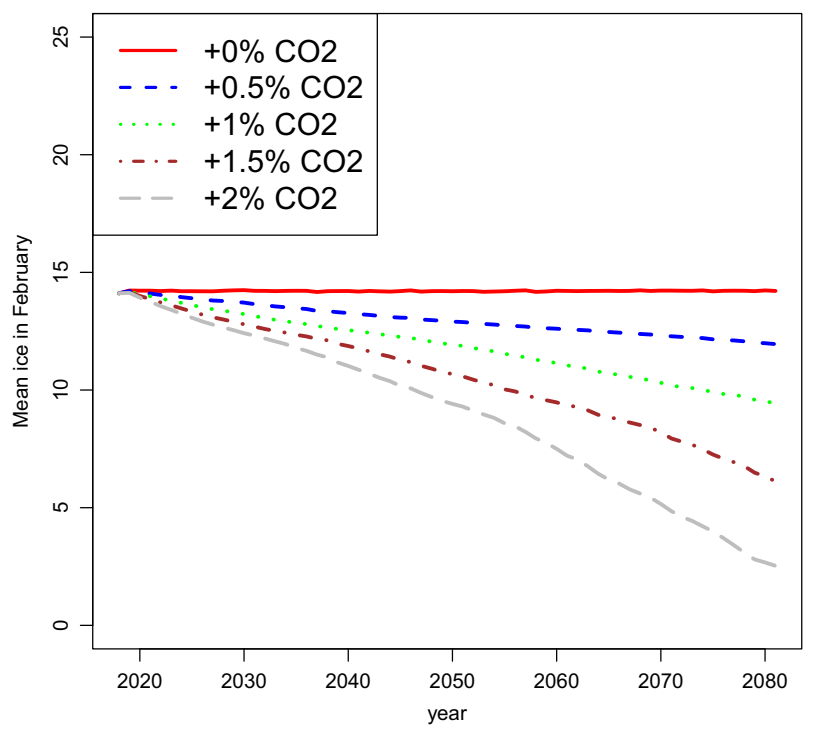

Fig. 7 Predicted Mean Arctic sea ice extent In February under alternative $\mathrm{CO}_{2}$ scenarios, 2018-2080

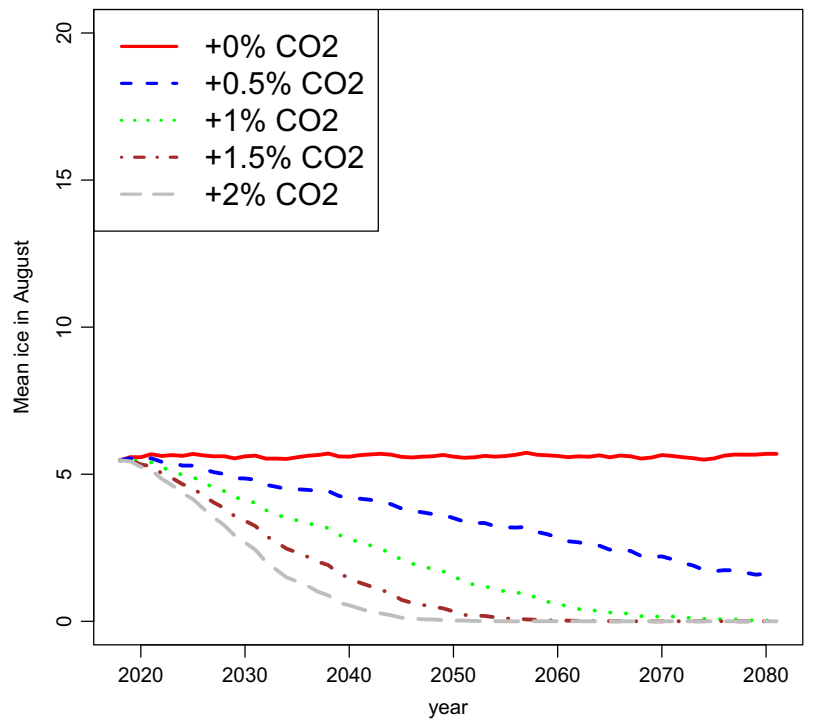

Fig. 8 Predicted mean Arctic sea ice extent in August under alternative $\mathrm{CO}_{2}$ scenarios, 2018-2080

would not change much if atmospheric $\mathrm{CO}_{2}$ remains unchanged. But over several decades, rising $\mathrm{CO}_{2}$ can have a large impact on Arctic sea ice extent. Figs 7 and 8 show that the $+2 \%$ scenario would significantly reduce the extent of Arctic sea ice by 2080. Importantly, this result would apply for both February and August.

Figures 9 and 10 provide additional evidence on the potential decline in Arctic sea ice. Using our quantile estimates of Eq. (2) and its forward simulations, Figs 9 and 10 report the evolving probability that all Arctic sea ice would disappear over the next 60 years under alternative $\mathrm{CO}_{2}$ scenarios. Such calculated probabilities are never 1 across all months within a year. In August, Fig. 10 shows that this probability would basically remain at zero under the $+0 \% \mathrm{CO}_{2}$ scenario. And Fig. 9 indicates that a similar result holds in February under all $\mathrm{CO}_{2}$ scenarios. But the probability of having "no Arctic sea ice in August" would rise over time as $\mathrm{CO}_{2}$ increases. By 2060, the probability would rise to 0.2 (or 20 percent chance) under the $+1 \% \mathrm{CO}_{2}$ scenario, to 0.8 (or 80 percent chance) under the $+1.5 \% \mathrm{CO}_{2}$ scenario, and to 1 (or 100 percent chance) under the $+2 \% \mathrm{CO}_{2}$ scenario. These results

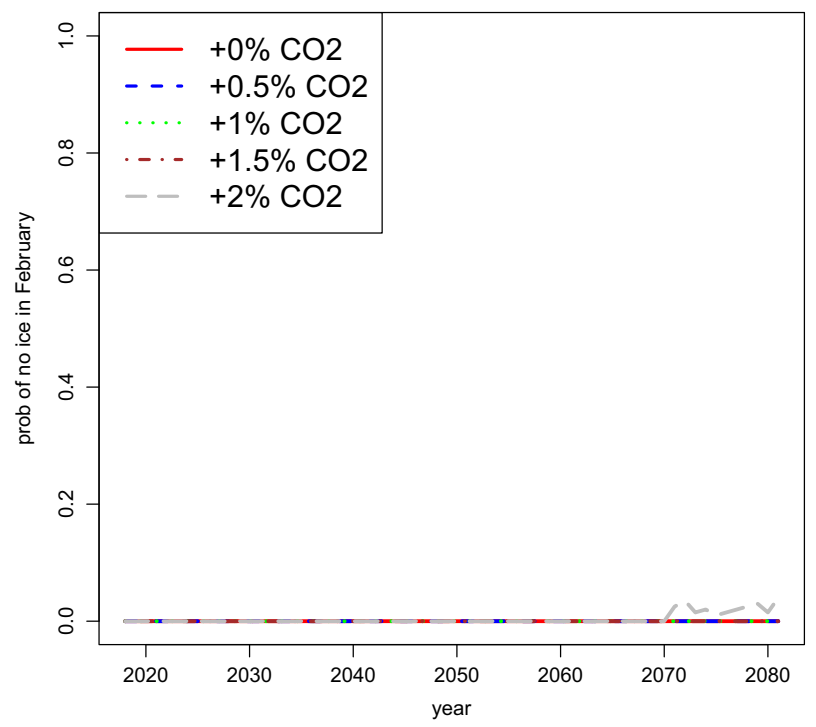

Fig. 9 Probability of "No Arctic Sea Ice" in February under alternative $\mathrm{CO}_{2}$ scenarios, 2018-2080

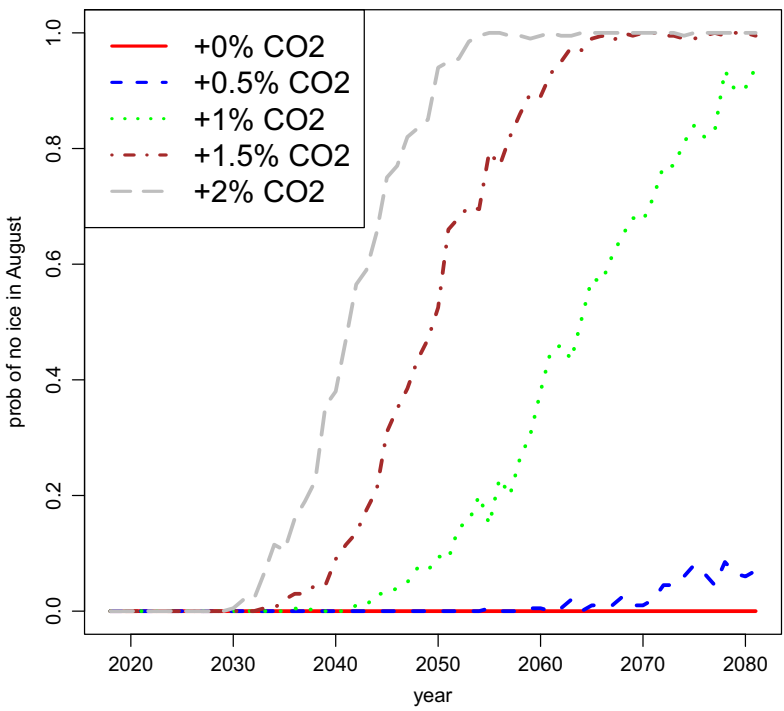

Fig. 10 Probability of "No Arctic Sea Ice" in August under alternative $\mathrm{CO}_{2}$ scenarios, 2018-2080

document substantial long term impacts of rising $\mathrm{CO}_{2}$. They add to the evidence that significant increases in atmospheric $\mathrm{CO}_{2}$ could lead to an ice-free Arctic sea in the summer by the end of the $21^{\text {st }}$ Century. ${ }^{32-37}$ Note that our analysis cannot speak to (ir) reversibility in polar ice dynamics. But our finding of potentially large long term impacts of $\mathrm{CO}_{2}$ presents additional evidence on the magnitude of climate change effects.

In summary, we find that the negative effect of atmospheric $\mathrm{CO}_{2}$ is stronger in the upper tail of the ice distribution, and that atmospheric $\mathrm{CO}_{2}$ tends to reduce ice seasonality. We show how nonlinear feedback effects contribute to dynamic instability. In particular, we find evidence of increasing instability in Arctic sea ice, especially during the summer months. The rising summer instability occurs across quantiles, indicating that it is due to the joint effects of rising $\mathrm{CO}_{2}$ and nonlinear feedback (and not due to outside shocks). While we do not identify a so-called "tipping point", the increasing instability is a cause for concern. Using our estimates, our analysis provides additional information on how 
quickly Arctic sea ice could disappear over the next decades as atmospheric $\mathrm{CO}_{2}$ rises.

\section{METHODS}

The evolution of Arctic sea ice extent is driven by energy flux. In general, this evolution can be written as

$\mathrm{Ice}_{t}=f\left(\mathrm{~S}_{t}-L_{t}, H A_{t}, H O_{t}\right)$,

where ice ${ }_{t}$ is Arctic sea ice extent at time $t_{1} S_{t}$ is solar radiation in the Arctic, $L_{t}$ is outgoing long wave radiation and $\left(H A_{t}, H O_{t}\right)$ are net heat transfers toward the Arctic from the atmosphere $\left(H A_{t}\right)$ and ocean $\left(H O_{t}\right)^{3,7}$ Each of the determinants in (1) involve temporal effects and dynamics. ${ }^{5,18,19}$ Solar influx in the Arctic region, $S_{t}$, is strongly seasonal due to the inclination of earth's axis, leading to sea-ice buildup in the winter and ice melting in the summer. This strong seasonality tends to hide other factors affecting Arctic sea ice dynamics. Heat loss $L_{t}$ is affected by many factors. One factor is ice albedo, as the amount of solar energy absorbed is higher in an ice-free ocean than under ice cover. Ice albedo provides positive feedback that affects ice dynamics, a contributing factor to the recent decline in Arctic sea ice. ${ }^{1,2,9,10,13,20,21}$ Another factor involves the effects of greenhouse gases that restrict long-wave radiation to space, leading to higher temperatures and the melting of Arctic sea ice extent. ${ }^{22,23}$ Finally, atmospheric and ocean circulations are important, as heat exchange between the poles and equatorial regions have large effects on polar climate, ${ }^{24-26}$ although the associated dynamic effects on Arctic sea ice remain imperfectly understood. ${ }^{15} \mathrm{~A}$ key issue is that each of these factors has its own dynamics and their feedback effects can interact with each other, making it more difficult to assess each factor's net effect on the evolution of Arctic sea ice. As noted in the introduction, nonlinear dynamics and the interactions between strong seasonality and anthropogenic $\mathrm{CO}_{2}$ emissions make relying on covariance analysis alone (e.g., using autocovariance or spectral analysis) unfitting.

Equation (1) constitutes a structural model of the evolution of Arctic sea ice extent. But alternative models can provide valid specifications of Arctic sea ice dynamics. In time series analysis, one such model is a "final form" expressing current $i c e_{t}$ as a function of its lagged values. ${ }^{27}$ Zellner and Palm ${ }^{27}$ show that a "final form" model can capture all the relevant dynamics in (1), while it is easier to estimate. On that basis, our empirical analysis relies on the specification and estimation of a "final form" model of Arctic sea ice dynamics. Using monthly data on Arctic sea ice extent and atmospheric $\mathrm{CO}_{2}$ over the period 1979-2017, we address three important questions: 1/ Has there been a change in Arctic sea ice seasonality? 2/ Is there any evidence of rising dynamic instability in Arctic sea ice? and 3/ What is the role of rising atmospheric $\mathrm{CO}_{2}$ in the evolution of Arctic sea?

To answer these questions, we first explored alternative specifications of "final form" models of Arctic sea ice extent dynamics. We used the Bayesian Information Criterion (BIC) as a measure of goodness-of-fit to choose among alternative specifications (see the online supplemental material to this article). This exploration led us to selecting the following model for our analysis

$$
\begin{gathered}
\text { ice }_{t}=\beta_{0}+\beta_{c} \mathrm{CO}_{2, t}+\sum_{j \in J} \beta_{j} \text { ice }_{t-j}+\beta_{n} \sin \left(\frac{2 \pi t}{12}\right)+\beta_{s} \cos \left(\frac{2 \pi t}{12}\right) \\
+\sum_{i>j} \sum_{j \in J} \beta_{j i} \text { ice }_{t-j} \times \text { ice }_{t-i}+\beta_{c n} \mathrm{CO}_{2, t} \sin \left(\frac{2 \pi t}{12}\right)+\beta_{c s} \mathrm{CO}_{2, t} \cos \left(\frac{2 \pi t}{12}\right)+e_{t},
\end{gathered}
$$

where ice $_{t}$ is an index of Arctic sea ice in the $t$-th month, $J=\{1,2,12\}$, the $\beta^{\prime} s$ are parameters to be estimated and $e_{t}$ is an idiosyncratic error term. As noted above, Eq. (2) is a "final form" model capturing all the relevant dynamics of Arctic sea ice.

Equation (2) is a stochastic nonlinear difference equation providing a representation of Arctic sea ice dynamics. The sine and cosine terms in (1) capture annual seasonality. With $J=\{1,2,12\}$, Eq. (2) involves dynamics of order 1, 2 and 12, with $y_{t-1}$ and $y_{t-2}$ reflecting shorter term dynamics while $y_{t-12}$ reflects longer term (i.e., inter-annual) dynamics. The specification (2) exhibits nonlinear dynamics through the interaction terms ice $_{t-j} \times$ ice $_{t-i}$. Finally, the effects of atmospheric carbon dioxide effects on Arctic sea ice are captured in (2) in linear form and as interactions with the sine and cosine terms. As such, the specification allows $\mathrm{CO}_{2}$ to affect the seasonality of Arctic sea ice. Equation (2) provides a representation of Arctic sea ice dynamics in a least three ways. First, it allows for changing seasonality over time. Second, it goes beyond the mean and variance analysis commonly found in previous research relying on autocorrelation or spectral analysis $\left(\right.$ e.g., ${ }^{28}$ ) Third, the nonlinear dynamics in (2) can capture feedbacks that affect the dynamic stability of ice (see the online supplemental material to this article). This last characteristic is particularly important in our analysis.

\section{DATA AVAILABILITY}

The data used in the analysis are available from the authors upon request.

\section{CODE AVAILABILITY}

The $\mathrm{R}$ software code used in the analysis is available from the authors upon request.

\section{ACKNOWLEDGEMENTS}

We would like to thank Daniel R. Chavas for useful comments on an earlier draft of the paper. This research was supported in part by a grant from the Graduate School, University of Wisconsin.

\section{AUTHOR CONTRIBUTIONS}

All authors researched, collated and wrote this paper.

\section{ADDITIONAL INFORMATION}

Supplementary information accompanies the paper on the npj Climate and Atmospheric Science website (https://doi.org/10.1038/s41612-019-0080-x).

Competing interests: The authors declare no competing interests.

Publisher's note: Springer Nature remains neutral with regard to jurisdictional claims in published maps and institutional affiliations.

\section{REFERENCES}

1. Budyko, M. I. The Effect of solar radiation variations on the climate of the earth. Tellus 21, 611-619 (1969).

2. Sellers, W. D. A Global climatic model based on the energy balance of the earthatmosphere system. J. Appl. Meteorol. 8, 392-400 (1969).

3. North, G. R., Cahalan, R. F. \& Coakley, J. Energy balance climate models. Rev. Geophys. 19, 91-121 (1981).

4. Crowley, T. J. Causes of climate change over the last 1000 years. Science 289, 270-277 (2000).

5. Zhang, J., Rothrock, D. \& Steele, M. Recent changes in arctic sea ice: the interplay between ice dynamics and thermodynamics. J. Clim. 13, 3099-3114 (2000).

6. Eisenman, I., Schneider, T., Battisti, D. S. \& Bitz, C. M. Consistent changes in the sea ice seasonal cycle in response to global warming. J. Clim. 24, 5325-5335 (2011).

7. Wagner, T. J. W. \& Eisenman, I. How climate model complexity influences sea ice stability. J. Clim. 28, 3998-4014 (2015).

8. Dansgaard, W. et al. Evidence of general indtability of past climate from a 250-kyr ice-core record. Nature 264, 218-220 (1993).

9. Lenton, T. M. et al. Tipping elements in the earth's climate system. Proc. Natl Acad. Sci. 105, 1786-1793 (2008).

10. Rosen, J. What Happens after the Ice goes. Nature 542, 7640 (2017).

11. Holloway, G. \& Sou, T. Has Arctic Sea Ice Rapidly Thinned? J. Clim. 15, 1691-1701 (2019).

12. Frances, J. A. Why are arctic linkages to extreme weather still up in the air? Bull. Am. Meteorol. Soc. 98, 2551-2557 (2017).

13. Kashiwase, H., Ohshima, K. I., Nihashi, S. \& Eicken, H. Evidence for ice-ocean albedo feedback in the arctic ocean shifting to a seasonal ice Zone. Sci. Rep. 7, 8170 (2017).

14. Kutzbach, J. E., Ruddiman, W. F., Vavrus, S. J. \& Philippon, G. Cliamte model simulation of anthropogenic influence on greenhouse-induced climate change (early agriculture to modern): the role of ocean feedbacks. Clim. Change 99, 351-381 (2010).

15. Bhattacharya, T., Tierney, J. E. \& DiNezio, P. Glacial reduction of the North American monsoon via surface cooling and atmospheric ventilation. Geophys. Res. Lett. 44, 5113-5122 (2017).

16. Semiletov, I., Makshtas, A. \& Akasofu, S. I. Atmospheric $\mathrm{CO}_{2}$ balance: the role of Arctic ice. Geophys. Res. Lett. 31, L05121 (2004).

17. Notz, D. \& Stroeve, J. Observed Arctic sea-ice loss directly follows anthropogenic $\mathrm{CO}_{2}$ emission. Science 354, 747-750 (2016).

18. Hunke, E. C. \& Dukowicz, J. K. An elastic-viscous-plastic model for sea ice dynamics. J. Phys. Oceanogr. 27, 1849-1867 (2002). 
19. Leppäranta, M. The Drift of Sea Ice (Springer, Berlin, 2004).

20. Ingram, W. J., Wilson, C. A. \& Mitchell, J. F. B. Modeling climate change: an assessment of sea ice and the surface albedo feedbacks. J. Geophys. Res. 94, 8609-8622 (1989).

21. Wagner, T. J. W. \& Eisenman, I. False alarms: how early warning signals falsely predict abrupt sea ice loss. Geophys. Res. Lett. 42, 333-341 (2015).

22. Weatherly, J. W. \& Zhang, Y. The Response of the polar regions to increased $\mathrm{CO}_{2}$ in a global climate model with elastic-viscous-plastic sea ice. J. Clim. 14, 268-283 (2001).

23. Johannessen, O. M. et al. Arctic climate change: observed and modelled temperature and sea-ice variability. Tellus A Dyn. Meteorol. Oceanogr. 56, 328-341 (2004).

24. O'Farrell, S. P. Investigation of the dynamic sea ice component of a coupled atmosphere-sea ice general circulation model. J. Geophys. Res. 103, 15751-15782 (1998).

25. Rignot, E. \& Robert, H. T. Mass balance of polar ice sheets. Science 297, 1502-1506 (2002)

26. Holland, M. M. \& Bitz, C. M. Polar amplification of climate change in coupled models. Clim. Dyn. 21, 221-232 (2003).

27. Zellner, A. \& Palm, F. Time series analysis and simultaneous equations econometric models. J. Econ. 2, 17-54 (1974).

28. Bushuk, M. \& Giannakis., D. The seasoanlity and interannual variabilty of Arctic sea ice reemergence. J. Clim. 30, 4657-4676 (2017).

29. Windnagel, A., Brandt, M., Fetterer, F. \& Meier, W. "Sea Ice Index Version 3 Analysis" NSIDC Special Report 19. https://nsidc.org/sites/nsidc.org/files/files/NSIDC-specialreport-19.pdf. (2017).

30. Tans, P. \& Keeling, R. Trends in atmospheric carbon dioxide NOAA/ESRL. www.esrl. noaa.gov/gmd/ccgg/trends. (20018).
31. Koenker, R. Quantile Regression. (Cambridge University Press, Cambridge, 2005).

32. Koenker, R. \& Xiao, Z. Quantile autoregression. J. Am. Stat. Assoc. 101, 980-990 (2006)

33. Kerr, R. A. Ice-Free Arctic Sea May be Years, Not Decades, Away. Science 337, 1591 (2012).

34. Overland, J. E. \& Wang, M. When will the summer Arctic be nearly sea ice free? Geophys. Res. Lett. 40, 2097-2101 (2013).

35. Jahn, A. Reduced probaility of ice-free summers for $1.5^{\circ} \mathrm{C}$ compared to $2{ }^{\circ} \mathrm{C}$ warming. Nat. Clim. Change 8, 409-413 (2018).

36. Screen, J. A. Arctic Sea Ice at 1.5 and $2{ }^{\circ} \mathrm{C}$. Nat. Clim. Change 8, 360-369 (2018)

37. Sigmond, M., Fyle, J. C. \& Swart, N. C. Ice-free Arctic projections under the parisagreement. Nat. Clim. Change 8, 404-408 (2018).

(i) Open Access This article is licensed under a Creative Commons Attribution 4.0 International License, which permits use, sharing, adaptation, distribution and reproduction in any medium or format, as long as you give appropriate credit to the original author(s) and the source, provide a link to the Creative Commons license, and indicate if changes were made. The images or other third party material in this article are included in the article's Creative Commons license, unless indicated otherwise in a credit line to the material. If material is not included in the article's Creative Commons license and your intended use is not permitted by statutory regulation or exceeds the permitted use, you will need to obtain permission directly from the copyright holder. To view a copy of this license, visit http://creativecommons. org/licenses/by/4.0/.

(c) The Author(s) 2019 